\title{
Efficacy of Oral Recombinant Methioninase and Eribulin on a PDOX Model of Triple-negative Breast Cancer (TNBC) Liver Metastasis
}

\author{
HYE IN LIM ${ }^{1,2,3}$, YU SUN ${ }^{1,2}$, QINGHONG HAN ${ }^{1}$, JUN YAMAMOTO ${ }^{1,2}$ and ROBERT M. HOFFMAN ${ }^{1,2}$ \\ ${ }^{1}$ AntiCancer Inc, San Diego, CA, U.S.A.; \\ ${ }^{2}$ Department of Surgery, University of California, San Diego, CA, U.S.A.; \\ ${ }^{3}$ Department of Surgery, Chinjujeil Hospital, Jinju, Republic of Korea
}

\begin{abstract}
Background/Aim: The aim of the present study was to identify effective drugs for a highly-aggressive livermetastasis of triple-negative breast cancer (TNBC) in a patientderived orthotopic xenograft (PDOX) mouse model. Drugs tested were oral recombinant methioninase (o-rMETase), lowdose eribulin and their combination. Materials and Methods: Patient-derived TNBC was implanted in the liver of nude mice by surgical hepatic implantation. Two weeks after transplantation, 32 mice were randomized ( $n=8$ per group) into a phosphate-buffered saline vehicle-control group; o-rMETasetreatment group (100 units, o-rMETase, oral, daily for 2 weeks); eribulin-treatment group $(0.05 \mathrm{mg} / \mathrm{kg}$ intraperitoneally once per week for 2 weeks); or combination-treatment group (100 units r-METase, oral, daily for 2 weeks $+0.05 \mathrm{mg} / \mathrm{kg}$ eribulin intraperitoneally once per week for 2 weeks). Results: After 2 weeks, the three treatment groups exhibited significantlyinhibited TNBC growth in the liver compared to the vehiclecontrol group $(p \leq 0.05)$. Conclusion: o-rMETase and low-dose eribulin monotherapy and their combination were efficacious against the highly-aggressive TNBC PDOX growing in the liver. The TNBC PDOX model can be used to identify highly-effective drugs for therapy of TNBC with liver metastasis.
\end{abstract}

Triple-negative breast cancer (TNBC) is negative for estrogen receptor, progesterone receptor and human epidermal-growth-factor receptor 2 (1). TNBC is highly

This article is freely accessible online.

Correspondence to: Hye In Lim, Department of Surgery, Chinjujeil Hospital, Jinju, Republic of Korea. Tel: +82 1099330009, e-mail: vastprogress@ naver.com and Robert M. Hoffman, AntiCancer, Inc, 7917 Ostrow St, San Diego, CA, 92111, U.S.A. Tel: +1 8586542555, e-mail: all@anticancer.com

Key Words: Triple negative breast cancer, TNBC, patient-derived orthotopic xenograft, PDOX, liver metastasis, eribulin, oral recombinant methioninase, o-rMETase. recalcitrant to chemotherapy such as anthracyclines and taxanes and has very poor prognosis, as most patients die of metastatic disease $(2,3)$.

Eribulin is an anti-microtubule agent that prevents microtubule polymerization with anti-mitotic activity. Recently, eribulin was shown to be active clinically against metastatic breast cancer, increasing overall survival in the EMBRACE trial (4).

The patient-derived orthotopic xenograft (PDOX) mouse model, which mimics clinical cancer, was developed by our laboratory in 1991 (5). We established the first PDOX model of breast cancer, which showed metastases to the lung in 1993 (6). We previously developed PDOX models of TNBC (7-10) and showed the primary tumor to be sensitive to eribulin and oral recombinant methioninase (o-rMETase). We also developed a liver-metastasis PDOX model of TNBC (11). In the present study, we show that the liver-metastasis PDOX model is sensitive to low-dose eribulin and o-rMETase and their combination.

\section{Materials and Methods}

Mice. Female nu/nu nude female mice (AntiCancer Inc., San Diego, CA, USA), 4-6 weeks old, were used in this study. The breeding and maintenance of the nude mice are described in our previous reports $(7,8)$. All mouse studies were carried out under the National Institutes of Health Guide for the Care and Use of Animals (Assurance Number A3873-1).

Patient-derived TNBC and establishment of PDOX with liver metastasis. The TNBC tissue used was from a 74-year-old female patient diagnosed with invasive ductal-carcinoma in the right breast. Breast-conserving surgery was performed at the Department of Surgery, Samsung Medical Center, Seoul, Korea as previously described elsewhere $(9,10)$. Written informed-consent was obtained from the patient with Samsung Medical Center Institutional Review Board approval. The TNBC tumor had initially been established subcutaneously in nude mice, and PDOX models were subsequently established $(9,10)$. The liver-metastasis model was established by implanting a tumor fragment, harvested from subcutaneous growth, 


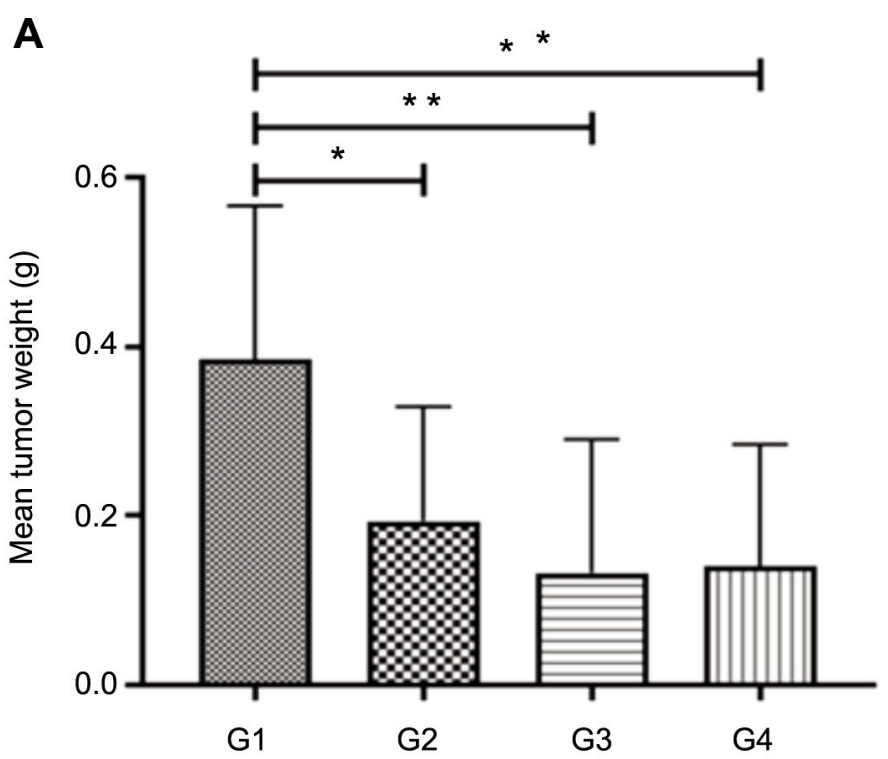

B

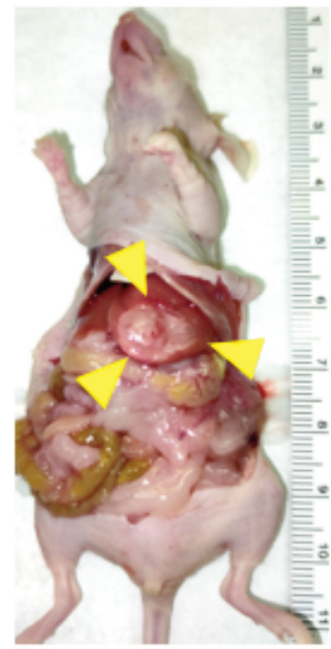

G1

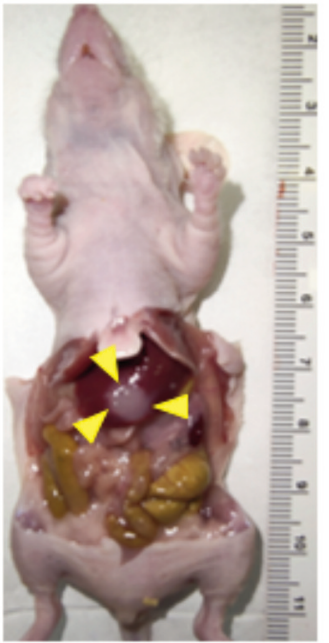

G2

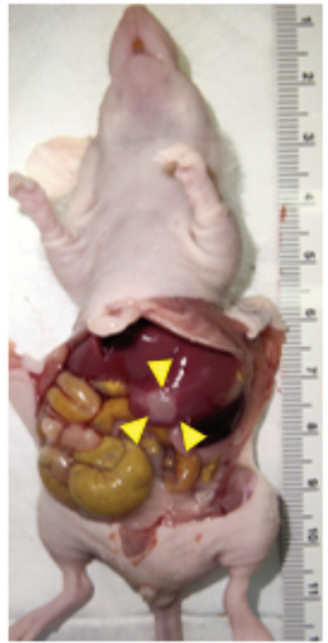

G3

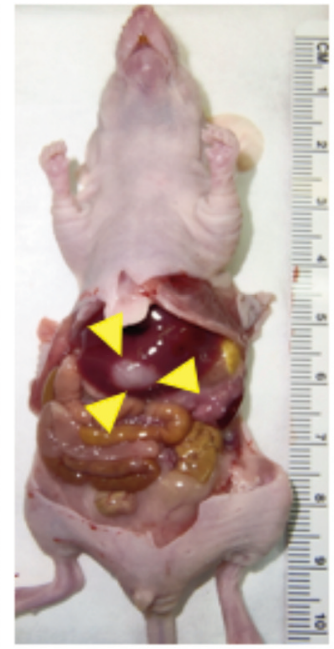

G4

Figure 1. Comparison of inhibitory efficacy on the liver-metastasis triple-negative breast cancer (TNBC) patient-derived orthotopic xenograft. A: Final tumor weight in the phosphate-buffered-saline-vehicle (G1); oral-recombinant-methioninase (o-rMETase) monotherapy (G2); eribulin monotherapy (G3); and combination therapy (o-rMETase + eribulin; G4) groups. B: Representative images of TNBC growing in the liver at necropsy. Data are the mean $\pm S D$ of eight animals. Significantly different at $* p=0.05$ and $* * p<0.01$ compared to G1.

into the liver (11). The tumor fragments were implanted into the left liver-lobe by surgical hepatic-implantation to establish the livermetastasis PDOX model. The wound was closed with a 7-0 nylon suture (11).

Treatment dose and schedule. Two weeks after implantation, the TNBC PDOX mouse models were randomized into four groups of eight mice each: Phosphate-buffered saline (PBS) vehicle-control group (0.2 ml PBS orally, daily for 2 weeks); o-rMETase-treatment group (100 units of rMETase orally daily for 2 weeks); low-doseeribulin-treatment group $(0.05 \mathrm{mg} / \mathrm{kg}$ eribulin intraperitoneally once per week for 2 weeks); combination-treatment group (100 units r-METase orally daily for 2 weeks plus eribulin intraperitoneally at $0.05 \mathrm{mg} / \mathrm{kg}$ once per week for 2 weeks).

Body weights were measured twice a week, and a monitoring curve was plotted. The study was terminated 14 days after the initiation of treatment. All mice were sacrificed, the tumor was completely resected and weighed using an electronic scale. 


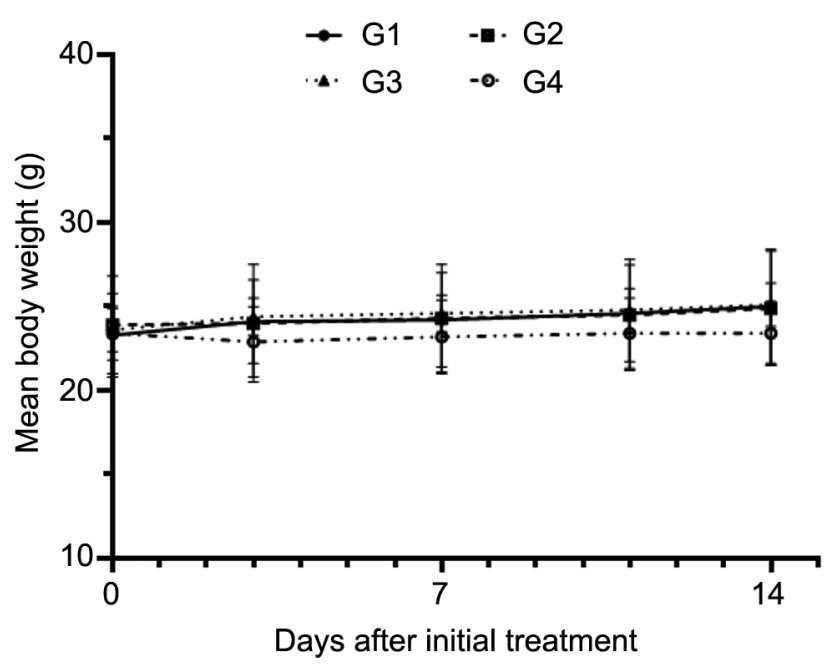

Figure 2. Body-weight monitoring in the phosphate-buffered-salinevehicle (G1); oral-recombinant-methioninase (o-rMETase) monotherapy (G2); eribulin monotherapy (G3); and combination therapy (o-rMETase + eribulin; G4) groups during the treatment period. There was no significant difference between the groups. Data are the mean $\pm S D$ of eight animals.

Statistical analyses. All statistical analyses were performed with $\mathrm{R}$ ver. 3.6.1 ( $\mathrm{R}$ foundation, Vienna, Austria). All data were analyzed using one-way ANOVA followed by Dunnett's correction. Graphs show the mean tumor volume and number of mice, and error bars represent standard deviation. A probability value of $p \leq 0.05$ was defined as statistically significant.

\section{Results}

As shown in Figure 1, after 2 weeks of treatment, all the treatment groups exhibited significantly lower weight of the TNBC in the liver compared to the PBS-vehicle control ( $p=0.05$ for o-rMETase monotherapy; $p=0.01$ for eribulin monotherapy and combination treatment groups).

Clinical observation of animals during the study showed no physical or behavioral signs that indicated adverse effects due to any treatment. A stable body weight in the treated groups, without significant loss compared to the vehicle control, indicated that both eribulin and o-rMETase had no obvious toxicity (Figure 2).

\section{Discussion}

Our previous studies have shown eribulin is highly effective against PDOX TNBC (7-10). The present study showed that low-dose eribulin is effective against a liver-metastasis TNBC PDOX.

We also previously showed that o-rMETase is active against the primary TNBC PDOX (9) with a tendency for efficacy against liver metastasis of TNBC (11). The present study showed o-rMETase significantly inhibited growth of livermetastasis TNBC. o-rMETase is of particular importance as it targets the methionine addiction of cancer, which is a fundamental and general hallmark of cancer discovered by us (12-20) and which is termed the Hoffman effect (21-23). Future clinical studies will combine low-dose chemotherapy with orMETase for TNBC to overcome the recalcitrance of this disease. o-rMETase has currently shown clinical efficacy against advanced prostate cancer (24-26). Previous clinical studies have shown injectable methioninase is safe in metastatic breast-cancer patients (27).

\section{Authors' Contributions}

HIL and RMH conceived the study. HIL, YS and JY performed the experiments. QH produced the methioninase. HIL and YS wrote the manuscript. RMH revised the manuscript.

\section{Acknowledgements}

This paper is dedicated to the memory of A.R. Moossa, MD, Sun Lee, MD, Professor Li Jiaxi and Masaki Kitajima, MD.

\section{References}

1 Lin NU, Vanderplas A, Hughes ME, Theriault RL, Edge SB, Wong YN, Blayney DW, Niland JC, Winer EP and Weeks JC: Clinicopathologic features, patterns of recurrence, and survival among women with triple-negative breast cancer in the National Comprehensive Cancer Network. Cancer 118(22): 5463-5472, 2012. PMID: 22544643. DOI: 10.1002/cncr.27581

2 Carey LA, Perou CM, Livasy CA, Dressler LG, Cowan D, Conway K, Karaca G, Troester MA, Tse CK, Edmiston S, Deming SL, Geradts J, Cheang MC, Nielsen TO, Moorman PG, Earp HS and Millikan RC: Race, breast cancer subtypes, and survival in the Carolina Breast Cancer Study. JAMA 295(21): 2492-2502, 2006. PMID: 16757721. DOI: 10.1001/jama.295.21.2492

3 Dent R, Trudeau M, Pritchard KI, Hanna WM, Kahn HK, Sawka CA, Lickley LA, Rawlinson E, Sun P and Narod SA: Triplenegative breast cancer: clinical features and patterns of recurrence. Clin Cancer Res 13(15 Pt 1): 4429-4434, 2007. PMID: 17671126. DOI: 10.1158/1078-0432.CCR-06-3045

4 Cortes J, O'Shaughnessy J, Loesch D, Blum JL, Vahdat LT, Petrakova K, Chollet P, Manikas A, Diéras V, Delozier T, Vladimirov V, Cardoso F, Koh H, Bougnoux P, Dutcus CE, Seegobin S, Mir D, Meneses N, Wanders J, Twelves C and EMBRACE (Eisai Metastatic Breast Cancer Study Assessing Physician's Choice Versus E7389) investigators: Eribulin monotherapy versus treatment of physician's choice in patients with metastatic breast cancer (EMBRACE): a phase 3 open-label randomised study. Lancet 377(9769): 914-923, 2011. PMID: 21376385. DOI: 10.1016/S0140-6736(11)60070-6

5 Fu XY, Besterman JM, Monosov A and Hoffman RM: Models of human metastatic colon cancer in nude mice orthotopically constructed by using histologically intact patient specimens. Proc Natl Acad Sci USA 88(20): 9345-9349, 1991. PMID: 1924398. DOI: $10.1073 /$ pnas.88.20.9345 
6 Fu X, Le P and Hoffman RM: A metastatic orthotopic-transplant nude-mouse model of human patient breast cancer. Anticancer Res 13(4): 901-904, 1993. PMID: 8352558.

7 Yamamoto J, Murata T, Tashiro Y, Higuchi T, Sugisawa N, Nishino H, Inubushi S, Sun YU, Lim H, Miyake K, Hongo A, Nomura T, Saitoh W, Moriya T, Tanino H, Hozumi C, Bouvet M, Singh SR, Endo I and Hoffman RM: A triple-negative matrix-producing breast carcinoma patient-derived orthotopic xenograft (PDOX) mouse model is sensitive to bevacizumab and vinorelbine, regressed by eribulin and resistant to olaparib. Anticancer Res 40(5): 2509-2514, 2020. PMID: 32366395. DOI: 10.21873/anticanres.14221

8 Yamamoto J, Murata T, Sugisawa N, Higuchi T, Tashiro Y, Nishino H, Inubushi S, Sun YU, Lim H, Miyake K, Shimoya K, Nomura T, Kurebayashi J, Tanino H, Hozumi C, Bouvet M, Singh SR, Endo I and Hoffman RM: Eribulin regresses a cisplatinum-resistant rare-type triple-negative matrix-producing breast carcinoma patient-derived orthotopic xenograft mouse model. Anticancer Res 40(5): 2475-2479, 2020. PMID: 32366391. DOI: 10.21873/anticanres.14217

9 Lim HI, Hamada K, Yamamoto J, Han Q, Tan Y, Choi HJ, Nam SJ, Bouvet $\mathrm{M}$ and Hoffman RM: Oral methioninase inhibits recurrence in a PDOX mouse model of aggressive triplenegative breast cancer. In Vivo 34(5): 2281-2286, 2020. PMID: 32871751. DOI: 10.21873 /invivo.12039

$10 \mathrm{Lim} \mathrm{HI}$, Yamamoto J, Inubushi S, Nishino H, Tashiro Y, Sugisawa N, Han Q, Sun YU, Choi HJ, Nam SJ, Kim MB, Lee JS, Hozumi C, Bouvet M, Singh SR and Hoffman RM: A single low dose of eribulin regressed a highly aggressive triple-negative breast cancer in a patient-derived orthotopic xenograft model. Anticancer Res 40(5): 2481-2485, 2020. PMID: 32366392. DOI: 10.21873/anticanres. 14218

11 Lim HI, Yamamoto J, Han Q, Sun YU, Nishino H, Tashiro Y, Sugisawa N, Tan Y, Choi HJ, Nam SJ, Bouvet M and Hoffman RM: Response of triple-negative breast cancer liver metastasis to oral recombinant methioninase in a patient-derived orthotopic xenograft (PDOX) model. In Vivo 34(6): 3163-3169, 2020. PMID: 33144420. DOI: 10.21873/invivo.12151

12 Hoffman RM and Erbe RW: High in vivo rates of methionine biosynthesis in transformed human and malignant rat cells auxotrophic for methionine. Proc Natl Acad Sci USA 73(5): 1523-1527, 1976. PMID: 179090. DOI: 10.1073/pnas.73.5.1523

13 Hoffman RM, Jacobsen SJ and Erbe RW: Reversion to methionine independence in simian virus 40-transformed human and malignant rat fibroblasts is associated with altered ploidy and altered properties of transformation. Proc Natl Acad Sci USA 76(3): 1313-1317, 1979. PMID: 220612. DOI: 10.1073/ pnas.76.3.1313

14 Coalson DW, Mecham JO, Stern PH and Hoffman RM: Reduced availability of endogenously synthesized methionine for Sadenosylmethionine formation in methionine-dependent cancer cells. Proc Natl Acad Sci USA 79(14): 4248-4251, 1982. PMID: 6289297. DOI: $10.1073 /$ pnas.79.14.4248

15 Hoffman RM and Jacobsen SJ: Reversible growth arrest in simian virus 40-transformed human fibroblasts. Proc Natl Acad Sci USA 77(12): 7306-7310, 1980. PMID: 6261250. DOI: 10.1073/pnas.77.12.7306
16 Yamamoto J, Han Q, Inubushi S, Sugisawa N, Hamada K, Nishino H, Miyake K, Kumamoto T, Matsuyama R, Bouvet M, Endo I and Hoffman RM: Histone methylation status of $\mathrm{H} 3 \mathrm{~K} 4 \mathrm{me} 3$ and $\mathrm{H} 3 \mathrm{~K} 9 \mathrm{me} 3$ under methionine restriction is unstable in methionine-addicted cancer cells, but stable in normal cells. Biochem Biophys Res Commun 533(4): 10341038, 2020. PMID: 33019978. DOI: 10.1016/j.bbrc.2020.09.108

17 Stern PH, Wallace CD and Hoffman RM: Altered methionine metabolism occurs in all members of a set of diverse human tumor cell lines. J Cell Physiol 119(1): 29-34, 1984. PMID: 6707100. DOI: $10.1002 /$ jcp.1041190106

18 Stern PH and Hoffman RM: Elevated overall rates of transmethylation in cell lines from diverse human tumors. In Vitro 20(8): 663-670, 1984. PMID: 6500606. DOI: 10.1007/ BF02619617

19 Hoffman RM: Development of recombinant methioninase to target the general cancer-specific metabolic defect of methionine dependence: a 40-year odyssey. Expert Opin Biol Ther 15(1): 21-31, 2015. PMID: 25439528. DOI: 10.1517/14712598. 2015.963050

20 Yamamoto J, Inubushi S, Han Q, Tashiro Y, Sun Y, Sugisawa N, Hamada K, Nishino H, Aoki Y, Miyake K, Matsuyama R, Bouvet M, Endo I and Hoffman RM: Cancer-specific overmethylation of histone H3 lysines is linked with methionine addiction and malignancy. bioRxiv, 2021.DOI: 10.1101/2020.12.04.412437

21 Kaiser P: Methionine dependence of cancer. Biomolecules 10(4): 568, 2020. PMID: 32276408. DOI: 10.3390/biom10040568

22 Lauinger L and Kaiser P: Sensing and Signaling of Methionine Metabolism. Metabolites 11(2):83, 2021. PMID: 33572567. DOI: $10.3390 /$ metabo 11020083

23 Borrego SL, Fahrmann J, Hou J, Lin DW, Tromberg BJ, Fiehn O and Kaiser P: Lipid remodeling in response to methionine stress in MDA-MBA-468 triple-negative breast cancer cells. J Lipid Res 62:100056, 2021. PMID: 33647277. DOI: 10.1016/j.jlr.2021.100056

24 Han Q, Tan Y, Hoffman RM: Oral dosing of recombinant methioninase is associated with a 70\% drop in PSA in a patient with bone-metastatic prostate cancer and $50 \%$ reduction in circulating methionine in a high-stage ovarian cancer patient. Anticancer Res 40(5): 2813-2819, 2020. PMID: 32366428. DOI: 10.21873/anticanres.14254

25 Han Q and Hoffman RM: Lowering and stabilizing PSA levels in advanced-prostate cancer patients with oral methioninase. Anticancer Res 41(4): 1921-1926, 2021. PMID: 33813397. DOI: 10.21873/anticanres.14958

26 Han Q and Hoffman RM: Chronic treatment of an advanced prostatecancer patient with oral methioninase resulted in long-term stabilization of rapidly rising PSA levels. In Vivo 35(4):2171-2176, 2021. PMID: 34182494. DOI: $10.21873 /$ invivo.12488

27 Tan Y, Zavala J Sr, Xu M, Zavala J Jr, and Hoffman RM: Serum methionine depletion without side effects by methioninase in metastatic breast cancer patients. Anticancer Res 16(6C):39373942,1996. PMID: 9042316. 